\title{
3D Printing Applications in Construction from The Past and into The Future
}

\author{
M. Ammar Alzarrad, $\mathrm{PhD}^{\mathrm{a}}$, Souhail Elhouar, $\mathrm{PhD}, \mathrm{PE}^{\mathrm{a}^{*}}$ \\ ${ }^{a}$ Bradley University, $1501 \mathrm{~W}$. Bradley Ave, Peoria, IL 61625, USA
}

\begin{abstract}
The advent of 3D printing technology may very well be remembered as one of the most important technological advances of the early twenty-first century. This technology is transforming the dynamics of the manufacturing world in ways that may have not been thought possible a couple of decades ago. 3D printing is now being used in medicine and dentistry to make prosthetic parts, sensors, and medical models among a number of other applications. The versatility of the types of materials that can be 3D printed makes the process extremely useful. The technology is being used in different industries to produce various parts and components for generally lower costs while achieving a better quality. This is either achieved by 3D printing the parts themselves or the molds that would eventually be used to make the parts. However, the construction industry has been slow in adopting this technology for many reasons, many of which still need to be investigated so a way can be found around them. In this paper the authors first examine the history of 3D printing applications in the construction industry. They then provide an overview of recent attempts at applying the technology while discussing the successes and challenges encountered. They finally propose solutions for resolving some of the identified challenges to help the industry move forward in taking advantage of this emerging and potentially beneficial technology.
\end{abstract}

(C) 2019 The Authors. Published by Budapest University of Technology and Economics \& Diamond Congress Ltd.

Peer-review under responsibility of the scientific committee of the Creative Construction Conference 2019.

Keywords: 3D printing, construction automation, construction technology.;

\section{Introduction}

Dictionary.com defines 3D printing as "a printing process that involves making three-dimensional objects from digital models by applying many thin layers of a quick-drying material on top of each other" [1]. The technology became possible because of significant advances in both computer and materials technologies that have been taking place in recent decades. 3D printing has gained substantial attention in all the manufacturing industries in the past few years. Considering the adoption of new technology, it is well established that the construction industry is generally lagging in this area. Many new experiments have been conducted in the construction industry to explore the full potential that 3D printing can bring. However, these experiments are very fragmented [2]. A critical review of the history and current development of 3D printing in the construction industry is therefore needed. This paper, aims to: (1) examine the history of 3D printing applications in the construction industry; (2) provide an overview of recent attempts at applying the technology while discussing the successes and challenges encountered; (3) propose solutions for resolving some

*Corresponding author: Author email: selhouar@fsmail.bradley.edu 
Alzarrad \& Elhouar/Proceedings of the Creative Construction Conference (2019) 103

https://doi.org/10.3311/CCC2019-103

of the identified challenges to help the industry move forward in taking advantage of this emerging and potentially beneficial technology.

\section{A Historic Overview of 3D-Printing}

The first 3D printing efforts are granted to Dr. Hideo Kadoma for his development of a rapid prototyping technique in 1981. Dr. Kadoma developed a system of printing solid layers of fast drying photopolymers that resembled a crosssectional slice of a CAD model, and he called it Rapid Prototyping (RP) [3].

Three years later, Charles Hull patented Stereolithography which is a technique that utilizes the reaction between a liquid photopolymer and an Ultraviolet (UV) laser beam. When exposed to the UV light, the liquid photopolymer will instantly turn each layer into a solid plastic shape that is consistent with the 3D CAD model. Stereolitography was the first technology of rapid prototyping which means fast, precise and repeatable production of items usually with computer support. In 1992, Hull's company, 3D Systems, produced the SLA-1 which was the worlds' first commercial Sereolithography Apparatus (SLA) [4].

In 1987, Larry Hornbeck of Texas Instruments created Digital Light Processing (DLP) technique. This technique has many applications in the production of projectors and 3D printing. DLP technology uses digital micromirrors laid out on a semiconductor chip. Both DLP and SLA work with photopolymers, but they use different light source. DLP uses more traditional sources like arc lamps. Also, DLP uses a liquid crystal display panel that is being applied to the entire surface of the building material. DLP also uses a liquid plastic resin as a printing material. The resin quickly toughens when exposed to a large amount of light. DLP printing speed is fast compared to SLA. DLP creates more robust 3D objects with excellent resolution. It also uses less material which reduces cost and material waste. That same year, Carl Deckard introduced the Selective Laser Sintering machine (SLS) which is a similar technology that utilizes a powder photopolymer reaction rather than liquid [5].

In 1989, Scott Crump a co-founder of Stratasys Inc. filed a patent for Fused Deposition Modelling (FDM). FDM is a proprietary technology that is still held by the Stratasys Inc company today, and it is also the process used by many of the entry-level 3D printing machines [5].

Other 3D printing technologies and methods were also emerging during these years, namely Ballistic Particle Manufacturing (BPM) originally developed by William Masters, Laminated Object Manufacturing (LOM) originally developed by Michael Feygin, Solid Ground Curing (SGC) originally presented by Itzchak Pomerantz et al and 'three dimensional printing' (3DP) originally developed by Emanuel Sachs [5].

Throughout the 1990's and early 2000's many innovative technologies continued to be introduced, still focused mainly on industrial applications, and they were still mostly processes for prototyping applications. Research and Development were also being led by advanced technology providers for customized tooling, casting, and direct manufacturing applications. This saw the rise of new terminology, namely Rapid Tooling (RT), Rapid Casting and Rapid Manufacturing (RM). In 2005, the American Society for Testing and Materials (ASTM) recognized Additive Manufacturing (AM) as the standard term for all of these processes. ASTM defines additive manufacturing as "a process of joining materials to make objects from 3D model data, usually layer upon layer" [6].

The construction industry is well-matched to 3D printing because the information needed to create a 3D item exists as a result of the design process, and the industry is already experienced in computer-aided manufacturing. 3D printing provides the ability to use different materials, freedom of design, and the ability to fabricate complex shapes onsite or offsite. Add to those characteristics the power of automated and autonomous production, and you have a near-perfect match for the construction industry needs [7]. However, it should be noted that the application of 3D printing in the construction industry is still in its early stages.

\section{3D-Printing Applications in Construction}

Construction 3D printing allows faster and more accurate construction of complex items as well as reducing labor costs and material waste. It might also enable construction to be undertaken in tough or dangerous environments not suitable for a human workforce such as in remote areas on earth and in space [8]. 
The first 3D printing attempt in the construction industry was in 1995, by Dr. Behrokh Khoshnevis. Dr. Khoshnevis used stereolithography technology to produce three-dimensional ceramic parts. A complicated ceramic part was produced although the mechanical properties of the part were not optimized [9]. In 1996, Dr. Behrokh Khoshnevis registered a patent entitled "Additive Fabrication Apparatus and Method". This patent reveals a device for producing 3D objects using additive fabrication methods. The device includes two nozzles for delivering fluid materials, two supply means for carrying the fluid materials to the nozzles, and two control means for moving and positioning the nozzles. An additional feature of the device is the use of trowels, which allow fast creation of smooth surfaces with high precision. The trowels permit formation of different shapes using only the two trowels, instead of using a variety of tools needed in traditional plastering [9]. Fig. 1. Shows Dr. Khoshnevis new device.

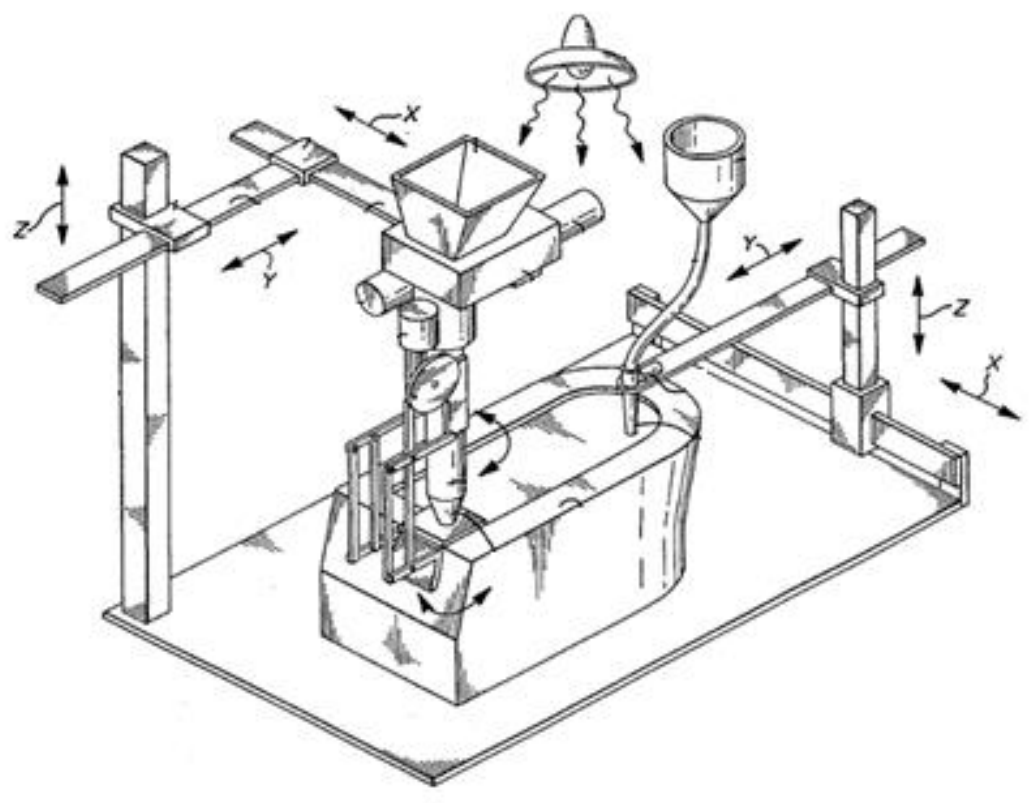

Fig. 1. Dr. Khoshnevis 3D printing device (adapted from Hinczewski,1998 [9]).

In 2001, Dr. Khoshnevis printed a wall using an FDM 3D printer that is mounted on a robotic arm to extrude concrete layers. Dr. Khoshnevis called this new technology Contour Crafting (CC). Contour Crafting can be defined as "an additive fabrication technology that uses computer control to exploit the superior surface-forming capability of troweling to create smooth and accurate planar and free form surfaces out of extruded materials" [10]. The Contour Crafting (CC) technology demonstrated all the qualities needed to use additive manufacturing on construction sites: reduction in costs, materials waste and accidents, faster construction speed, complex architectural shapes, and more. Contour Crafting also provides flexibility in building concrete shapes that were very hard to achieve in the traditional pouring methods; with that, houses can be built efficiently and environmentally friendlier [11].

In recent years and as technology improved, the use of 3D printing has been expanded to construction products other than ceramic. For example, 3D printers can now print plastic and nylon products which are commonly used as plug fixtures, window frame fixtures and plumbing fittings in building projects. More importantly, concrete printing has been proven to be feasible in printing geometrically complicated concrete products [12]. The size of the concrete products was limited using 3D printing. For example, the 3D printer in Lim et al. (2012) could only handle a print dimension up to $5.4 \mathrm{~m}(\mathrm{~L}) \times 4.4 \mathrm{~m}(\mathrm{~W})$ and $5.4 \mathrm{~m}(\mathrm{H})$. However, such size would produce enough capacity to print basic precast concrete components. As such, the main issue of the use of 3D printers to produce construction parts is not related to the size, but rather whether there are enough flexibility and customization demands that can support the use of such technology to achieve economies of scale [13].

The popularity of the 3D printing technology has seen recently a significant increase with many new companies, including some backed up by prominent names from the construction industry and academia. This led to several 
important milestones, such as the first 3D printed building and the first 3D printed bridge [14]. However, the application of 3D printing in construction is still in its infancy and is bound by many limitations. 3D printing is not an isolated solution that can solve all the problems in the construction industry. There are several requirements, such as the scale of the project and printing materials, which should be fulfilled in order for the printing technology to perform at its maximum potential. Some of the challenges to 3D printing in construction are dealing with various trades that required the use of different materials and construction methods. Further, using completely automated 3D printing techniques to create a full house is still a challenge [14].

\section{Challenges of 3D printing in construction}

Many researchers argued that large scale buildings might not be printed using 3D printing technologies because of the size of 3D printers [15]. Gibson et al. (2002) said that most 3D machines had a relatively small build envelope. As such, the size of the printed model would be limited. Berman (2012) also argued that 3D printing technology was commonly useful to create small part sizes [15]. Many other scholars have also stated that the main limitation of 3D printing technology was the size of the printer needed to print the item [16].

Most 3D printers were small when the technology trend started. It remained unclear whether the technology could be used to print large-scale models or buildings as the size of 3D printers was directly related to the models or buildings it could print. However, in recent years, with the new development of 3D printers, there have been a lot of large-scale models or buildings that were printed using large-scale 3D printers [17].

In addition to the size of the printer, materials played a significant role in 3D printing. The printing materials should have some basic features such as quick hardening in order to be used in 3D printing [18]. There were many studies which found that the strength and stability of the printed products using current printing materials (such as plaster) might prevent the technology from being used in large-scale models or buildings. For example, Khoshnevis et al. (2001) found that although plaster has been frequently used as a printing material because it was commercially available, cheap, light in weight and quick hardening, the material demonstrated low wet-strength and a larger than $3 \%$ shrinkage [18]. Similarly, although clay demonstrated a better wet-strength compared with plaster, the stability of the printed products has only been tested in small object sizes [18]. The low availability of high-strength printing materials also led to the speculation that 3D printing might not be useful to create large-scale models or buildings.

However, recently, various materials have been modified and proved to be effective as high-strength printing materials. In order to be used as a printing material, concrete needed to have an acceptable degree of extrudability so that it can be extruded from the nozzle of the printer [19]. In addition, the concrete should bond together to form each layer and have adequate buildability characteristics to enable it to lay down correctly, stay in position and be stiff enough to support further layers without collapsing [19]. By changing the sand/binder proportions and the dosages of other admixtures in the mix design, a variety of compressive strength have been achieved, with the highest up to $107 \mathrm{MPa}$ (at 28 days). As such, it is realistic to assume that the strength of the printed concrete is high enough to be used in large-scale building projects as concrete of $60-100 \mathrm{MPa}$ is usually used in these projects [19].

All in all, 3D printing can be used to print large-scale buildings. However, there is low demand for small sizes and customized products in the construction industry when compared with other industries [20]. In addition, the materials (i.e. clay and concrete) need to be improved in terms of brittleness so they can be used to print large-scale buildings.

3D printing may also be more expensive than conventional construction due to the high cost of 3D printers and the fact that most people in the industry are unfamiliar with $3 \mathrm{D}$ printing technologies and applications. Although $3 \mathrm{D}$ printing will minimize the material waste, it incurs high up-front costs to create the digital model [21].

\section{Current Trends in 3D-Printing}

The initial point for any 3D printing method is the creation of a 3D digital model, which can be developed using a variety of 3D software programs. Then it is exported to a file in a common 3D data exchange format. For the 3D printing industry, the most popular format is STL (Standard Tessellation Language format). Next, for the majority of 3D printing technologies, the saved data is processed to decompose the model into slices. This results in a set of 2D 
Alzarrad \& Elhouar/Proceedings of the Creative Construction Conference (2019) 103

https://doi.org/10.3311/CCC2019-103

contour lines that are further processed to generate control commands to position the printing head or laser beams [21]. As suggested by Canessa et al. (2013). Fig. 2 shows the typical 3D printing work-flow.

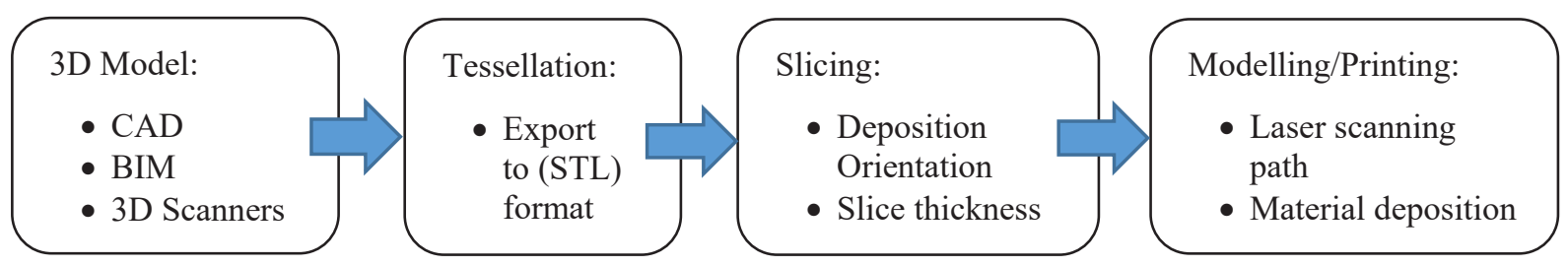

Fig. 2. 3D printing work-flow

While 2-D representations remain as the baseline method for project delivery in the construction industry, substantial time is needed to create digital models for 3D printing [21]. Traditional approaches of converting 2-D drawings to 3D models have many problems including low quality and inefficiency [22]. Building Information Modelling (BIM) is an emerging method for digital representation of physical and functional characteristics of a facility [23]. When compared with conventional 3D modeling tools, BIM covers not only geometry information but material performance (i.e., yield strength, tensile strength, shear modulus, thermal conductivity, etc.), spatial relationships and manufacture information [25]. Furthermore, objects in BIM are defined as parameters and relations to other objects. As such, one object change will trigger related objects to be changed automatically [24]. In the last few years, BIM has been proved as an effective method to facilitate 3D printing implementation in the construction industry [24]. BIM can be used in the 3D printing of small and large scale models and buildings.

BIM is more powerful than traditional tools in complex building design [25]. The interaction between 3D printing and BIM enhances the ability to produce 3D items rapidly from a BIM design without specialized or costly manufacturing equipment [25]. Most of BIM tools support the exporting process of generating a file in a proper format (i.e. STL) that can be directly converted into a set of instructions for the print [26]. Furthermore, BIM vendors such as Autodesk have collaborated with 3D printing providers to further simplify the process of 3D printing from BIM models. Further, 3D printing-integrated BIM supports the creative process of designers to produce variations of a single artifact or diverse artifacts at various stages of design [26]. Fig. 3 shows a 3D model that has been designed using BIM and printed using a $3 \mathrm{D}$ printer.

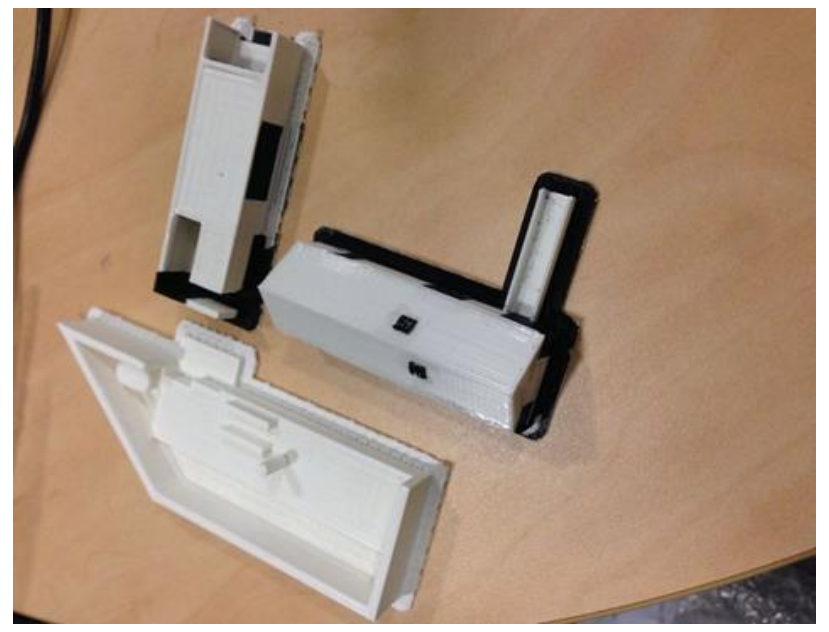

(a) 3D printed model

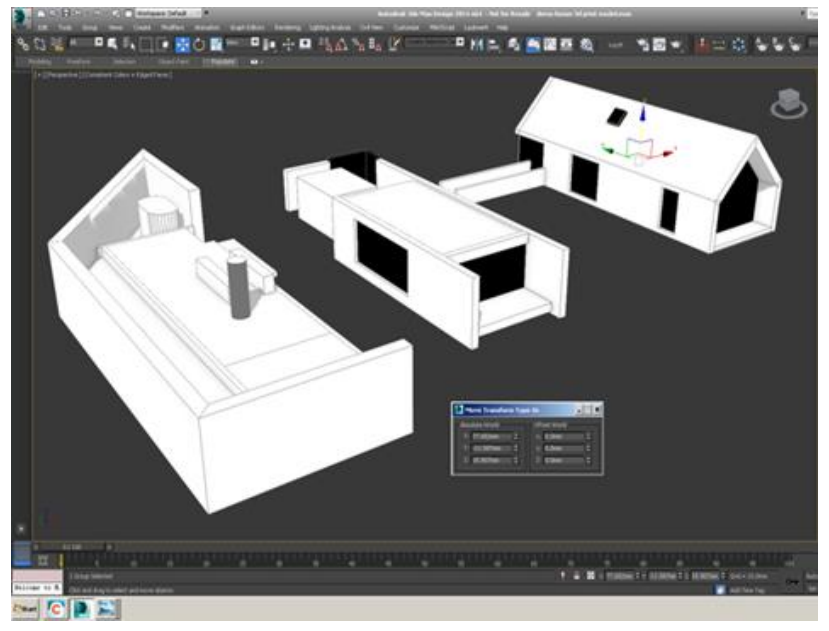

(b) 3D digital BIM model

Figure 3: BIM digital model and the 3D printed model [26] 
Although the use of BIM can help examine the printed projects at performance and assembly levels, the life cycle assessment of the printed projects is still vague. In addition, the degree of customization of the printed items has not yet been empirically examined in the construction industry. It is expected that by addressing these challenges, the construction industry could maximize the advantages of the 3D printing applications [26].

\section{Futuristic Perspective of 3D-Printing in Construction}

There are different views about where the 3D printing technology could be headed. Although 3D printing is still in its early days in the construction industry, the potential benefits seem to be driving the technology forward. Till today, there is no building that is fully printed [26], 3D printing could use the advancement of automation and robotics to automatically print a full large-model. Tomorrow's construction engineers and managers need to master the software skills on which 3D printing rests. Learning to co-work with automated and 3D printing technology will be more and more a very important requirement for the workers in the construction industry.

3D printing could also be a way to explore space. Applications of 3D printing to build in space are unlimited. 3D printing reduces time, cost, and health, and safety risks if used in space. As a result, NASA has launched the "3D Printed Habitat Challenge" to develop innovative 3D printing capabilities to build homes in space.

3D printing technology could be used to increase sustainability. Houses can be built based on the material life cycle, that can be used in evaluating the environmental sustainability of building materials. Creating sustainable buildings with complicated shapes and that are adapted to their surroundings may become one of the biggest advantages for 3D printing.

\section{Conclusion}

The presented research gives a brief overview of 3D printing in construction. Regardless of the future of 3D printing in construction, it is clear that it will change the construction industry forever. Whether this is in creating new shaped structures or providing cheap housing, the buildings of the future will most likely look much different than those of today. However, the use of $3 \mathrm{D}$ printing is also subject to a few prerequisite requirements, mainly on applicability in large-scale building projects, the development of BIM, the degree of requirements on customization, and the life cycle cost of 3D printed construction products.

\section{References}

[1] Retrieved from https://www.dictionary.com/browse/3d-printing.

[2] D. J. Murray, G. Edwards, J. G. Mainprize, O. Antonyshyn, Optimizing craniofacial osteotomies: applications of haptic and rapid prototyping technology. Journal of the American Association of Oral and Maxillofacial Surgeons, 66 (2008) 66 - 72. https://doi.org/10.1016/j.joms.2007.08.031

[3] P. Wu, J. Wang, X. Wang, A critical review of the use of 3-D printing in the construction industry. Automation in Construction Journal. 68 (2016) 21-31. https://doi.org/10.1016/j.autcon.2016.04.005

[4] Z. Malaeb, H. Hachen, A. Tourbah, T. Maalouf, N.E. Zarwi, F. Hamzeh, 3D concrete printing: Machine and mix design, International Journal of Civil Engineering and Technology. 6 (2015) 14-22.

[5] D. Goldman, History of 3D Printing: It's Older Than You Think. (2018, April 13). Retrieved on March 26, 2019, from https://www.autodesk.com/redshift/history-of-3d-printing/

[6] R. A. Buswell, R. C. Soar, A. G. F. Gibb, A. Thorpe, Freeform Construction: Mega-scale Rapid Manufacturing for construction. Automation in Construction, 16 (2007) 224-231. https://doi.org/10.1016/j.autcon.2006.05.002

[7] ASTM. F2792. 2012 Standard terminology for additive manufacturing technologies. West Conshohocken, PA: ASTM International, 2012 Retrieved on March 26, 2019, from www.astm.org.

[8] C.L. Thomas, T.M. Gaffney, S. Kaza, C.H. Lee, Rapid prototyping of large scale aerospace structures. 1996 IEEE Aerospace Applications Conference. Proceedings, IEEE, (1996) 219-230. https://doi.org/10.1109/AERO.1996.499663

[9] C. Hinczewski, S. Corbel, T. Chartier, Stereolithography for the fabrication of ceramic three-dimensional parts. Rapid Prototyping Journal 4 (1998) 104-111. https://doi.org/10.1108/13552549810222867

[10] J. Zhang, Z. Hu. BIM-and 4D-based integrated solution of analysis and management for conflicts and structural safety problems during construction: Principles and methodologies. Automation in construction 20 (2011) 155-166. https://doi.org/10.1016/j.autcon.2010.09.013

[11] S. Lim, R.A. Buswell, T.T. Le, S.A. Austin, A.G.F. Gibb, T. Thorpe, Developments in construction-scale additive manufacturing processes. Automation in Construction 21 (2012) 262-268. https://doi.org/10.1016/j.autcon.2011.06.010

[12] M. Yossef, A. Chen, Applicability and Limitations of 3D Printing for Civil Structures. Civil, Construction and Environmental Engineering Conference Presentations and Proceedings, (2015) pp. 35-49

[13] I. Gibson, T. Kvan, L.W. Ming, Rapid prototyping for architectural models. Rapid Prototyping Journal, 8 (2002) 91-95

[14] B. Berman, 3-D printing: the new industrial revolution. Business Horizons, 55 (2012) 155-162.

[15] T. Campbell, T. Williams, C. Ivanova, O. Garrett, could 3D printing change the world: technologies, potential, and implications of additive manufacturing. Atlantic Council: Washington, 2011. https://doi.org/10.1016/j.bushor.2011.11.003 


\section{Alzarrad \& Elhouar/Proceedings of the Creative Construction Conference (2019) 103 https://doi.org/10.3311/CCC2019-103}

[16] F. Liang, Y. Liang, Study on the status quo and problems of 3D printed buildings in China. Global Journal of Human-Social Science, 14 (2014) 7-10.

[17] S. Khoshnevis, S. Bukkapatnam, H. Kown, J. Saito, Experimental investigation of 660 contour crafting using ceramics materials. Rapid Prototyping Journal, 7 (2001) 32-41.

[18] T. Le, S. Austin, R. Buswell, R. Law, A. Gibb, T. Thorpe, Hardened properties of high-performance printing concrete, Cement and Concrete Research, 42 (2012) 558-566. https://doi.org/

[19] M. Yossef, A. Chen, Applicability and limitations of 3D printing for civil structures. The Proceedings of the 2015 Conference on Autonomous and Robotic Construction of Infrastructure. Ames. Iowa, (2015) 237-246.

[20] E. Canessa, C. Fonda, M. Zennaron, Low-Cost 3D printing for science, education sustainable development. Trieste: ICTP - The Abdus Salam International Centre for Theoretical Physics 2013.

[21] Y. Arayici, P. Coates, L. Koskela, M. Kagioglou, C. Usher, K. O'Reilly. BIM adoption and implementation for architectural practices. Structural survey, 29 (2011) 7-25. https://doi.org/10.1108/02630801111118377

[22] C. P. Eastman, R. Teicholz, R. Sacks and K. Liston. BIM handbook: A guide to building information modeling for owners, managers, designers, engineers and contractors, John Wiley \& Sons: 2011.

[23] W. Shou, J. Wang, X. Wang, H. Y. Chong. A Comparative Review of Building Information Modelling Implementation in Building and Infrastructure Industries. Archives of Computational Methods in Engineering, (2014) 1-18. https://doi.org/10.1007/s11831-014-9125-9

[24] Y. Chang, G. Shih, BIM-based Computer-Aided Architectural Design. Computer-Aided Design and Applications, 10 (2013) 97-109. https:// doi.org/10.3722/cadaps.2013.97-109

[25] R. Bogue, 3D printing: the dawn of a new era in manufacturing. Assembly Automation 33 (2013) 307-311. https://doi.org/10.1108/AA-06-2013-055

[26] D. Seo, H. Won. A Basic Study on Korean-style House Model Manufacturing with 3D Laser Printer Based on BIM (Building Information Modeling). Advanced Science and Technology Letters, 47 (2014), 21-24. https://doi.org/10.14257/ast1.2014.47.05 